\title{
Properties of a Solar Alumina-Borosilicate Sheet Glass
}

\author{
R. T. Coyle \\ M. A. Lind \\ J. E. Shelby \\ A. F. Shoemaker \\ J. Vitko
}
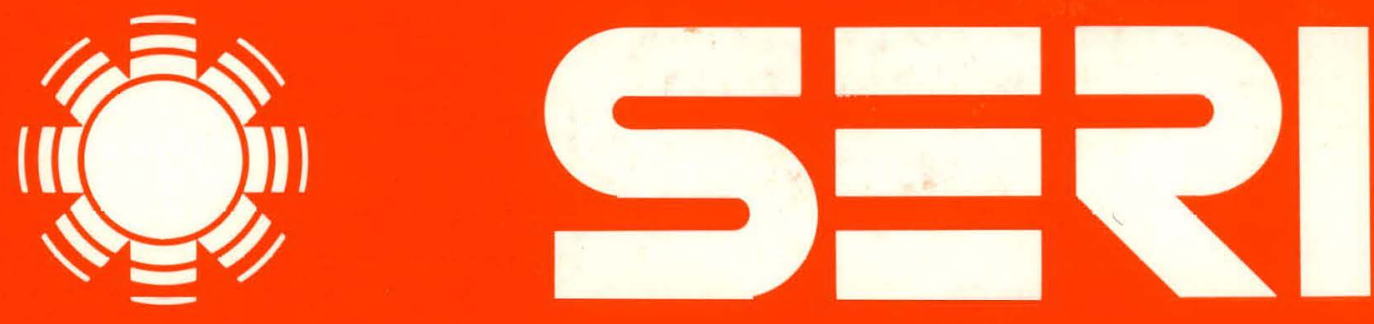

Solar Energy Research Institute

A Division of Midwest Research Institute

1617 Cole Boulevard

Golden, Colorado 80401

Operated for the

U.S. Department of Energy.

under Contract No. EG-77-C-01-4042 


\section{DISCLAIMER}

This report was prepared as an account of work sponsored by an agency of the United States Government. Neither the United States Government nor any agency Thereof, nor any of their employees, makes any warranty, express or implied, or assumes any legal liability or responsibility for the accuracy, completeness, or usefulness of any information, apparatus, product, or process disclosed, or represents that its use would not infringe privately owned rights. Reference herein to any specific commercial product, process, or service by trade name, trademark, manufacturer, or otherwise does not necessarily constitute or imply its endorsement, recommendation, or favoring by the United States Government or any agency thereof. The views and opinions of authors expressed herein do not necessarily state or reflect those of the United States Government or any agency thereof. 


\section{DISCLAIMER}

Portions of this document may be illegible in electronic image products. Images are produced from the best available original document. 
Printed in the United States of America Available from:

National Technical Information Service

U.S. Department of Commerce

5285 Port Royal Road

Springfield, VA 22161

Price:

Microfiche $\$ 3.00$

Printed Copy $\$ 4.00$

5. 42

NOTICE

This report was prepared as an account of work sponsored by the United States Government. Neither the United States nor the United States Department of Energy, nor any of their employees, nor any of their contractors, subcontractors, or their employees, makes any warranty, express or implied, or assumes any legal liability or responsibility for the accuracy, completeness or usefulness of any information, apparatus, product or process disclosed, or represents that its use would not infringe privately owned rights. 
SERI /TP-334-565

UC CATEGORY: UC-59c, 62e, 63e

PROPERTIES OF A SOLAR

ALUMINA-BOROS I L I CATE

SHEET GLASS

R. T. COYLE

M. A. LIND

J.E. SHELBY

A. F. SHOEMAKER

J. VITKO

JANUARY 1980

to Be Presented at the $12 \mathrm{TH}$

INTERNATIONAL GLASS CONGRESS,

Albuquerque, New Mexico,

JULY $6-11,1980$

PREPARED UNDER TASK No. 3141.00

\section{Solar Energy Research Institute}

1536 Cole Boulevard

Golden, Colorado 80401

A Division of Midwest Research Institute

Prepared for the

U.S. Department of Energy

ContractNo. EG $\cdot 77 \cdot C \cdot 01 \cdot 4042$ 


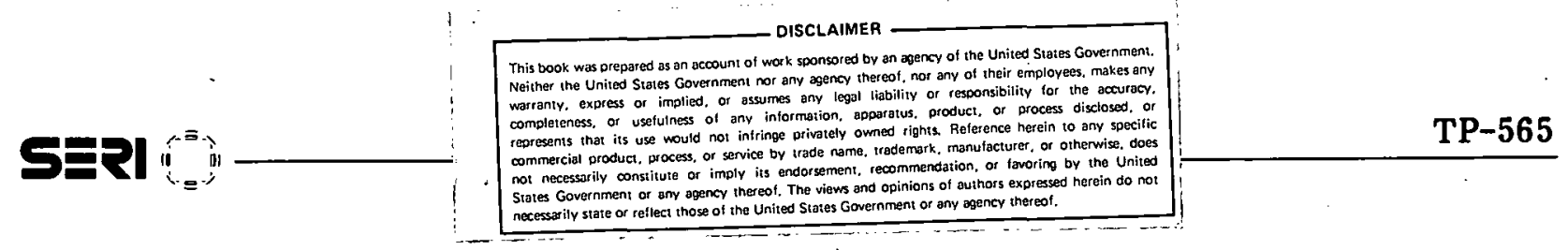

\title{
PROPERTIES OF A SOLAR ALUMINA-BOROSIICATE SHEET GLASS
}

\author{
R. T. Coyle \\ Solar Energy Research Institute \\ Golden, Colorado
}

J. E. Shelby and J. Vitko

Sandia Laboratories

Livermore, California

\author{
M. A. Lind \\ Pacific Nor thwest Laboratory \\ Richland, Washing ton \\ A. F. Shoemaker \\ Corning Glass Works \\ Corning, New York
}

\begin{abstract}
Solar energy applications place unique requirements on sheet glass including very low solar absorption, outstanding stability of absorption in the outdoor environment, low cost, and elastic formability for making concentrating mirrors. The Solar Energy Research Institute and Corning Glass Works have developed a new solar sheet glass. In evaluations reported in this paper, the new glass has shown outstanding chemical durability and optical and mechanical properties.
\end{abstract}

\section{INTRODUCTION}

A new sheet glass for solar energy applications including mirrors and glazings has been manufactured in a pilot-scale experiment sponsored by the Solar Energy Research Institute (SERI) at Corning Glass Works (CGW). This new glass was sought by SERI to satisfy unique solar requirements such as very low optical absorption, outstanding stability in the outdoor environment (minimizing absorption increase), low cost, and thinness for light weight and for elastic forming of parabolic mirrors.

The successful pilot-scale manufacturing experiment done at CGW and the results of tests reported in this paper indicate that the new sheet glass can meet these requirements. It should find a number of solar uses, such as glazings for passive solar and flatplate collector applications and for flat and curved solar mirror applications. In the balance of this paper we discuss the composition of this new glass, the forming technique used to make sheet glass, and the evaluation of the optical properties, chemical durability, and mechanical properties of the glasss.

\section{GLASS FORMING AND COMPOSITION}

The fusion process, patented by CGW, is one of several methods used to produce sheet glass. The advantages of this process are: (1) compositional flexibility; (2) capability to produce thin cross sections, i.e., $0.5 \mathrm{~mm}$; (3) ease of changing thickness; (4) excellent surface quality; and (5) operation in oxidizing conditions. Using current equipment, widths to $1.4 \mathrm{~m}$ and leng ths to slightly over $3 \mathrm{~m}$ can be achieved (modifications to present equipment could allow widths up to $1.8 \mathrm{~m}$ ).

The fusion process is based on an "overflow pipe." Molten glass flows from the forehearth into one end of a horizontally oriented hollow trough. An end view of this trough would show a V-shaped configuration. The gluss fills the internal cavity and overflows both sides of the trough. Edge-located pulling rolls are used with the surface tension of 
the molten glass to draw the glass uniformly down the exterior of the "pipe" to the apex of the V. There the glass "fuses" into a monolithic sheet. Heating and cooling equipment permits the judicious control of temperatures needed to carry the glass through the annealing and strain points. At the appropriate point in the cooling zone, the sheet is cut into required lengths and is then automatically transported to the edge stripping and final sizing station.

Corning Glass Works has developed a new glass composition (CGW-7809) for solar energy applications (Table 1). Some of the properties of the glass are shown in Table 2. The glass was designed to be compatible with the fusion sheet-forming process and to be melted at high rates for low production costs: Compositions originally considered ranged from "improved" soda-lime (float) glass to a hard borosilicate pharmaceutical composition (CGW-78ח6).

Table 1.

Composition of CGW-7809

Gilass

\begin{tabular}{lc}
\hline Oxide & \% \\
\hline $\mathrm{SiO}_{2}$ & 66 \\
$\mathrm{Al}_{2} \mathrm{O}_{3}$ & 9 \\
$\mathrm{~B}_{2} \mathrm{O}_{3}$ & 8 \\
$\mathrm{Na}_{2} \mathrm{O}$ & 9 \\
$\mathrm{CaO}$ & 2 \\
$\mathrm{~K}_{2} \mathrm{O}$ & 5 \\
$\mathrm{TiO}_{2}$ & 0.5 \\
$\mathrm{As}_{2} \mathrm{O}_{2}$ & 0.2 \\
$\mathrm{Fe}_{2} \mathrm{O}_{3}$ & $\mathbf{0 . 0 2}$ \\
\hline
\end{tabular}

'I'able 2.

Properties of CGW-7809 Glass

\begin{tabular}{lc}
\hline Softening Point, ${ }^{\circ} \mathrm{C}$ & 750 \\
Annealing Point, ${ }^{\circ} \mathrm{C}$ & 569 \\
Strain Point, ${ }^{\circ} \mathrm{C}$ & 529 \\
Expansion, $\left.{ }^{\circ} \mathrm{C}\right)^{-1}$ & $77 \times 10^{-7}$ \\
$0-300^{\circ} \mathrm{C}$ & \\
Polsson's Katio & 0.20 \\
Young's Modulus, psi & $11.1 \times 10^{6}$ \\
Density, g/cm & 2.44 \\
Index of Refraction & 1.509 \\
\hline
\end{tabular}

The low solar absorption of the new glass was obtained by: a) minimizing the total iron content; and b) adjusting the batch and melting conditions to oxidize all of the ferrous iron $\left(\mathrm{Fe}^{+2}\right)$ to ferric iron $\left(\mathrm{Fe}^{+3}\right)$. 
The levels of alumina and soda were adjusted in the composition to achieve a thermal expansion of $77 \times 10^{-7} /{ }^{\circ} \mathrm{C}$ to minimize thermal expansion differences with potential support materials. The resulting CGW-7809 composition represents a logical compromise among solar transmission, thermal expansion, life, and cost.

\section{SOLAR TRANSMITTANCE AND OPTICAL FLATNESS}

The spectral hemispherical transmittance of the CGW-7809 glass was evaluated by using an integrating sphere spectrophotometer. The high spectral transmittance of the 7809 glass differs markedly from the transmittance of the more common soda-lime float glass. The broad absorption band around $1100 \mathrm{~nm}$ in the soda-lime glass due to $\mathrm{Fe}^{+2}$ is conspicuously absent in the 7809 glass, as shown in Fig. 1. The transmittance of the 7809 glass is close to the theoretical maximum and shows little absorption, only reflective losses.

The solar transmittance was calculated from the spectral transmittance by weighting the measured values by the NASA AM 1.5 [Ref. 1] terrestrial solar spectral irradiance distribution. Table 3 compares the transmittance of the 7809 glass to other hightransmittance glasses that have been considered for solar energy conversion applications.

Table 3. Solar Transmittance of Various Glasses

\begin{tabular}{ccc}
\hline $\begin{array}{c}\text { Thick- } \\
\text { ness } \\
(\mathrm{mm})\end{array}$ & Type & Transmittance \\
\hline 1.0 & CGW-7809 fusion & 0.919 \\
1.5 & CGW-7809 fusion & 0.917 \\
1.5 & CGW-0317 fusion & 0.909 \\
2.8 & CGW-0317 fusion & 0.903 \\
3.2 & low-iron rolled & 0.913 \\
3.2 & low-iron float & $0.88-0.89$ \\
3.2 & regular float & $0.83-0.87$ \\
\hline
\end{tabular}

One property of glass that impacts the optical performance of solar reflectors is the optical flatness of the sheet. The instrument used to evaluate the "effective flatness," or figure, of the glass is shown in Fig. 2. It consists of a laser that directs a beam of light onto the glass at 45 degrees from the sample normal. The beam, which is specularly reflected from the lower surface of the glass sheet, intersects a linear position detector. The output from this detector, which is placed normal to the beam, is sensitive to small angular deviations of the beam reflected from the samples. Using simple geometry, the signal can be calibrated in terms of absolute variations.

In a typical measurement sequence, the glass is placed horizontally on the translation table. The linear displacement of the table is accomplished using a computer-controlled stepping motor. Normally, measurements are taken every 0.1 inch across the sample. Individual samples up to 24 inches in length can be accommodated. The angular deflection versus position data is stored in the computer for later analysis. 


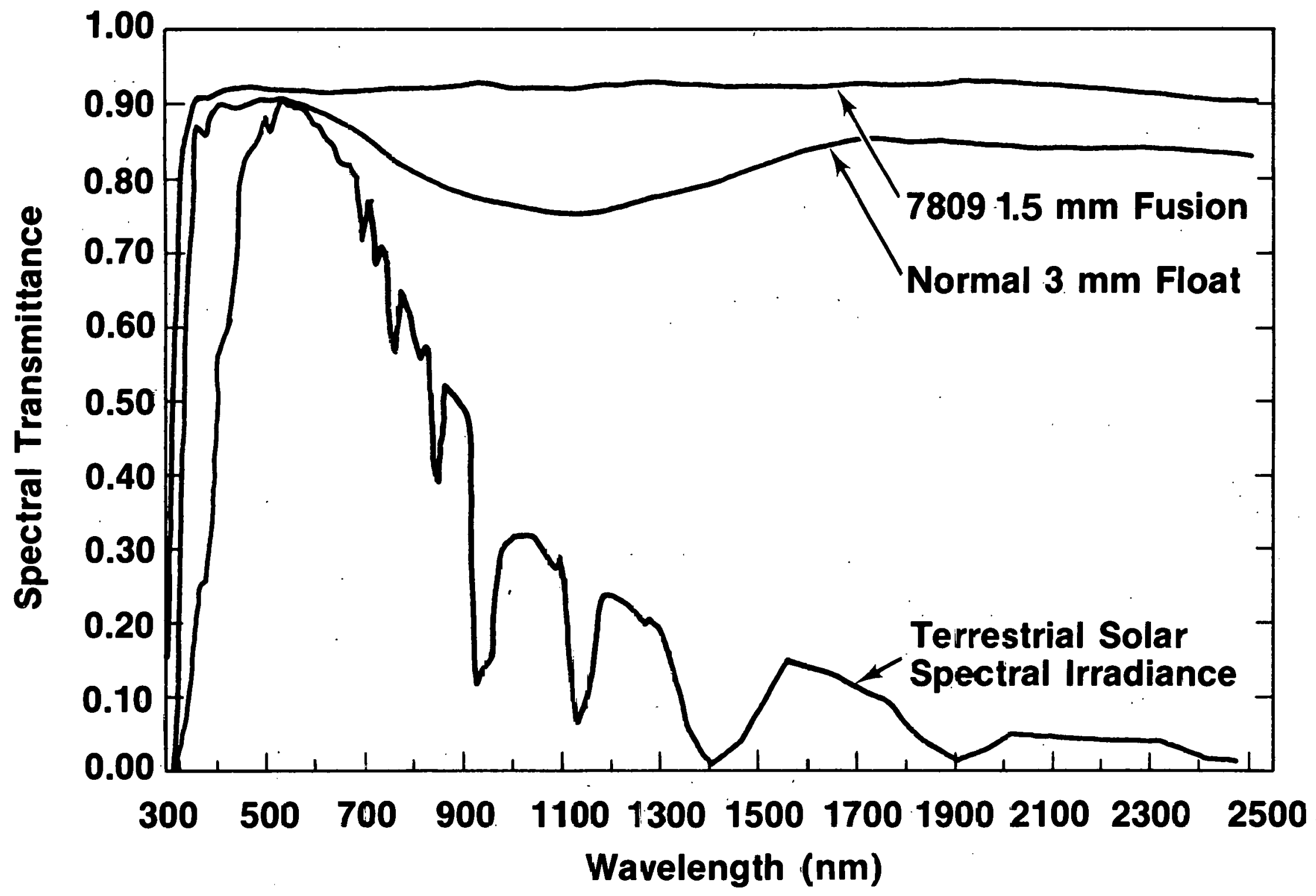

Figure 1. Transmittance in the Solar Spectrum and Relative Intensities of Solar Radiation 

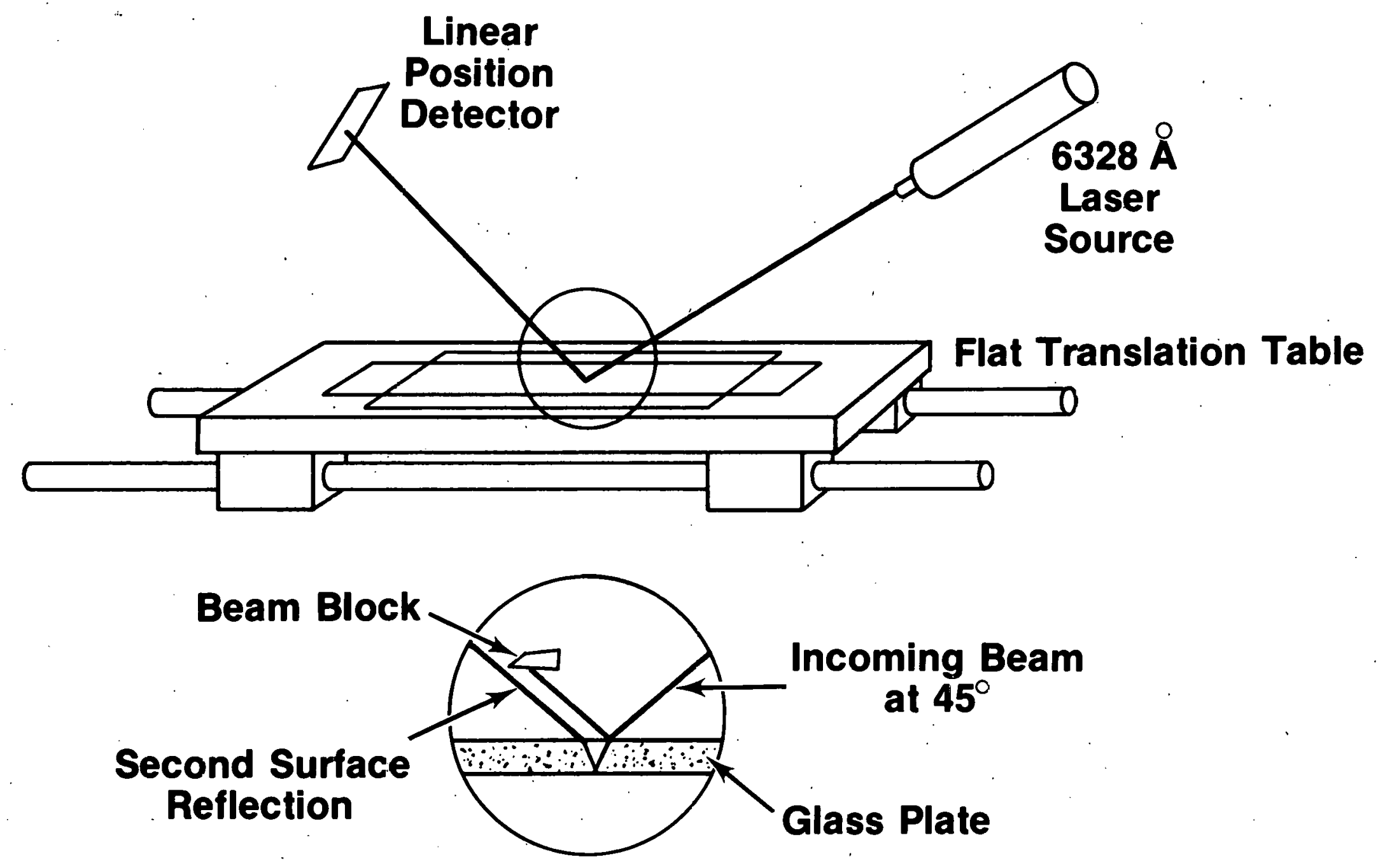

Figure 2. Laser Ray Trace Instrument for Glass Flatness Meaurements 
Figure 3 shows how the pilot run of CGW-7809 glass compares with production runs of typical soda-lime float and CGW-0317 aluminosilicate fusion glass. In the data presented, the long-period curvature corresponding to angular variations of up to one milliradian per foot has been subtracted. Thus only the short-period or high-amplitude variations that could affect reflector performance are indicated in the diagram. It is seen that the production fusion process can produce glass of float quality; production runs of CGW-7809 glass would be expected to have this surface quality.

\section{WEATHERING AND CHEMICAL DURABILTY}

Accelerated weathering studies were made on CGW-7809 glass specimens exposed at $70^{\circ} \mathrm{C}$ and $100 \%$ relative humidity in a controlled temperature-humidity chamber. Specimens were exposed for one to four weeks. The epccimcns wele lield so that the faces were in a vertical position so that any condensate that formed would tend to run off the specimen in a manner similar to that encountered in collectors. Observation of the specimens during treatment, however, indicated that the condensate remained on the surface of the glass for a number of days without any significant runoff.

The weathering behavior of the specimens was evaluated visually and by spectral measurements from 2600 to $200 \mathrm{~nm}$. None of the spectmens exhibited any visual signs of weathering when examined with the naked eye or under a microscope at 100-800 X. A very slight change in the optical properties of the specimens could be detected in the four-week exposure specimens, as shown in Fig. 4. This change is at least an order of magnitude less than that observed in float glasses under similar conditions. The degree of change increases with decreasing waveleng ths as would be expected for a loss due to a very slight increase in surface roughness. These observations indicate that this glass is an excellent material for use in conditions that require exposure to severe weathering environments.

The effect of $\mathrm{pH}$ on the chemical durability of CGW-7909 glass was determined ut $80^{\circ} \mathrm{C}$. Sper:imens were placed in $250 \mathrm{~cm}^{3}$ of solution of the desired $\mathrm{pH}$ and held fur seven day5. $\Lambda$ cid solutions were obtained using hydrochloric acid. Basic solutions were obtained by varying the concentration of sodium hydroxide. The specimens were weighed on an analytical balance to $\mathbf{\$ 0 . 0 0 0 ~} \mathrm{g}$ before and after exposure, Weight losses were normalized to the specimen area, which was approximately $10 \mathrm{~cm}^{2}$ in every case.

The effect of $\mathrm{pH}$ on the weight of CGW-7809 glass for one-week exposures is shown in Fig. 5. This glass exhibited excellent durability for pII values less than IU, with a rapid decrease in durability for higher $\mathrm{pH}$ solutions. This behavior is typical of most common silica te glasses, including float and sheet glasses and even viti'euus slllca. 'I'he specimen held at $\mathrm{pH}=13.8$ was the only specimen to exhihit detectable changes in opticul properties. That specinen was distinctly frosted and had a considerably decreased solar transmittance.

\section{SOLARIZATION}

The residual iron concentration in solar glasses, although low, is still sufficiently large that a change in the redox state ( $\mathrm{Fe}^{3+}$ to $\mathrm{Fe}^{2+}$ ratio) could have significant effects on the solar-weighted transmittance of these glasses. The existence of such changes in both field-exposed and simulator-exposed samples of potential solar glasses has recently been shown [2]. Such photo-induced redox reactions are believed to be sensitive to minor 


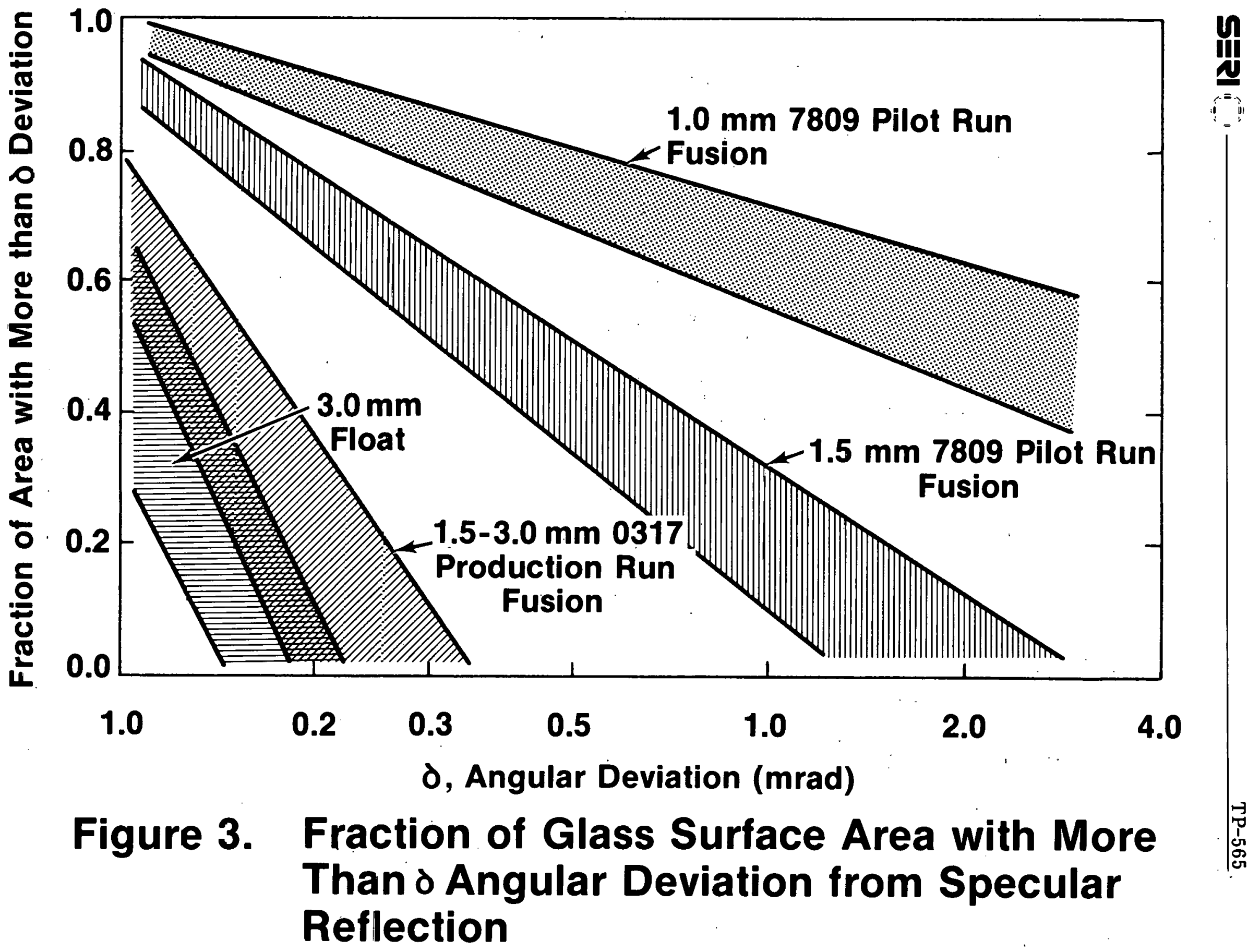




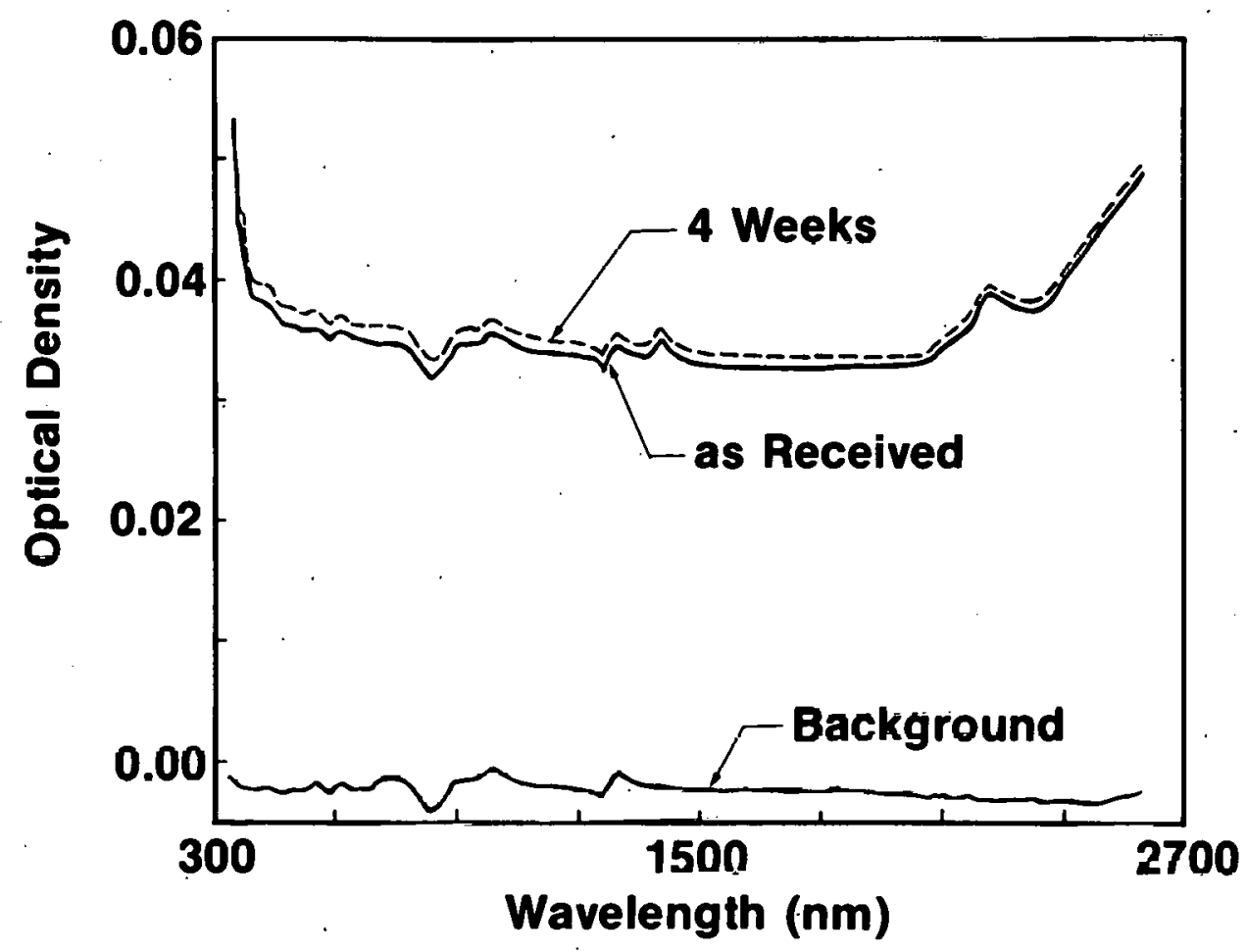

Figure 4. The Wavelength Dependence of the Optical Density for CGW7809 Glass after Accelerated Weathering

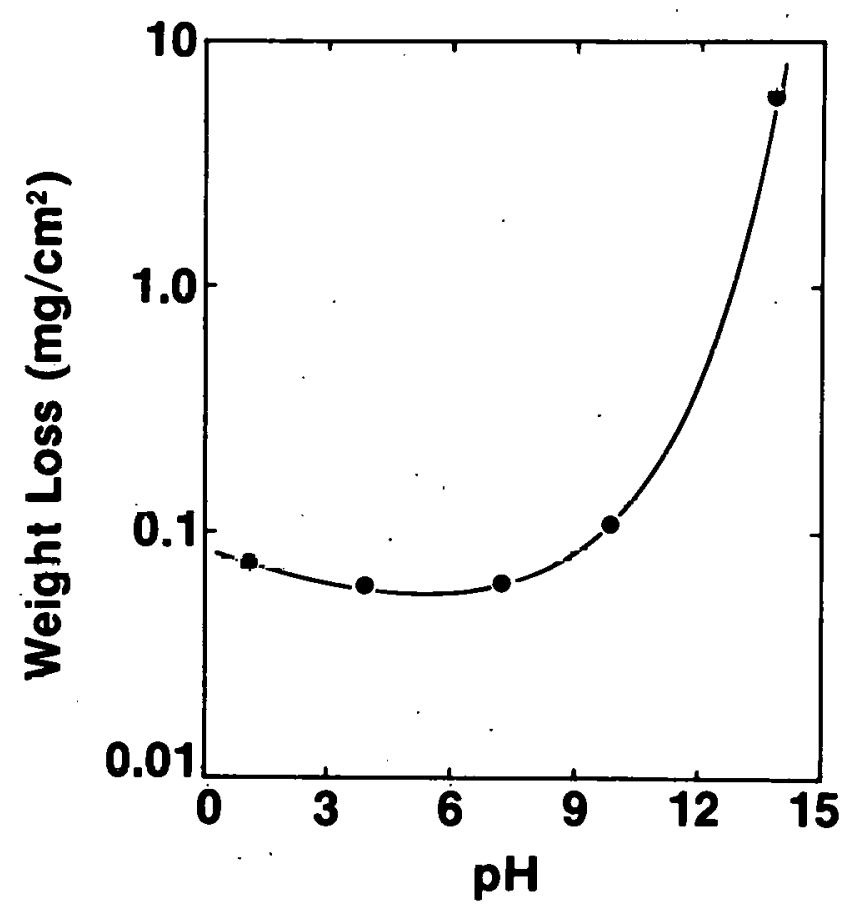

Figure 5. Effect of pH on Chemical Durability of CGW-7809 Glass 
changes in glass composition and melting atmosphere [3,4. Consequently, we have employed a solar simulator to screen samples for solarization tendencies.

The simulator is an Oriel Model 6730 solar simulator with a $1000 \mathrm{~W}$ ozone-free lamp, a $2^{\prime \prime} \times 2^{\prime \prime}$ output beam assembly, and an air mass 2 (A.M.2) filter. A radiant flux meter and narrow band interference filters were used to measure the spectral irradiance of the simulator over the waveleng th region $300-850 \mathrm{~nm}$. The measured irradiance was in good agreement with an A.M.2 spectrum, had an intensity of approximately 10 suns $\left(7.5 \mathrm{~kW} / \mathrm{m}^{2}\right)$ and remained constant over the course of the experiment (500 hours). Samples were placed in direct contact with a water-cooled copper plate to minimize sample heating. A Cary 171 spectrophotometer was used to measure the transmittance of the samples af ter 0,250 , and 500 hours.

The transmittance spectra of CGW-7809 glass after 0 and 500 hours of exposure to the simulator is shown in Fig. 6, as is the difference spectrum (spectrum af ter 0 hours minus spectrum after 500 hours). The spectra clearly show that any photo-induced change in optical density (O.D.) was less than 0.001 ; i.e., the samples did not solarize. Similar measurements on other potential solar glasses having a higher initial $\mathrm{Fe}^{2+}$ absorption exhibited solar-induced decreases in the O.D. at $1000 \mathrm{~nm}$ ranging from $0.002-0.01$.

\section{MECHANICAL PROPERTIES}

The fracture toughness, $\mathrm{K}_{\mathrm{IC}}$, of the $\mathrm{CGW}-7809$ glass was found to be $0.86 \pm 0.04 \mathrm{MPa} \sqrt{\mathrm{m}}$ versus $0.76 \pm 0.03 \mathrm{MPa} / \mathrm{m}$ for soda-lime float glass. The higher fracture toughness of this glass should give it an advantage in resisting hail impact and should provide more latitude in the handling of the glass, especially for thin sheets. The fracture toughness measurements were done with short bar specimens which measured $12.7 \times 11.05 \mathrm{x}$ $19.05 \mathrm{~mm}$ and are equivalent in mechanical behavior to the short rod specimens described by Barker [5]. A $0.38 \mathrm{~mm} \mathrm{V-shaped} \mathrm{slot} \mathrm{was} \mathrm{cut} \mathrm{in} \mathrm{each} \mathrm{specimen} \mathrm{so} \mathrm{that} \mathrm{it} \mathrm{could} \mathrm{be}$ loaded with a TerraTek Model 4201 fractometer, which cleaves the sample in a controlled manner. The measurements were done in dry nitrogen at $22^{\circ} \mathrm{C}$ as well as at $35 \%$ relative humidity and $22^{\circ} \mathrm{C}$ to insure that stress corrosion was not affecting the $\mathrm{K}_{\mathrm{IC}}$ measurement.

The short bar specimens and the fractometer were also used to make measurements of the slow crack growth in soda-lime glass and CGW-7809 solar glass, as shown in Fig. 7. The slow crack growth data were analyzed using a method developed by Barker [6]. The data of Weiderhorn [7] at $30 \%$ relative humidity and room temperature for soda-lime glass is in good agreement with our soda-lime data. It is seen, however, that the CGW-7809 data do not show region I behavior-the steeply sloping linear region at low stress intensity seen for soda-lime glass in the figure-at the stress-intensities used in this study. It is expected, however, that the region I stress corrosion behavior of the CGW-7809 glass would be superior, since its weathering resistance was found to be superior. Slow crack growth data is especially important in concentrating mirror applications where the glass is elastically formed into the desired profile. Tensile stresses on the order of 5-10 MPa may exist in the glass for tens of years in this application. Further work will be needed to measure the region I behavior of the 7809 glass.

\section{CONCLUSIONS}

A new sheet glass for solar energy applications has been developed and manufactured in a pilot-scale experiment. The optical flatness of this sheet promises to be equivalent to 


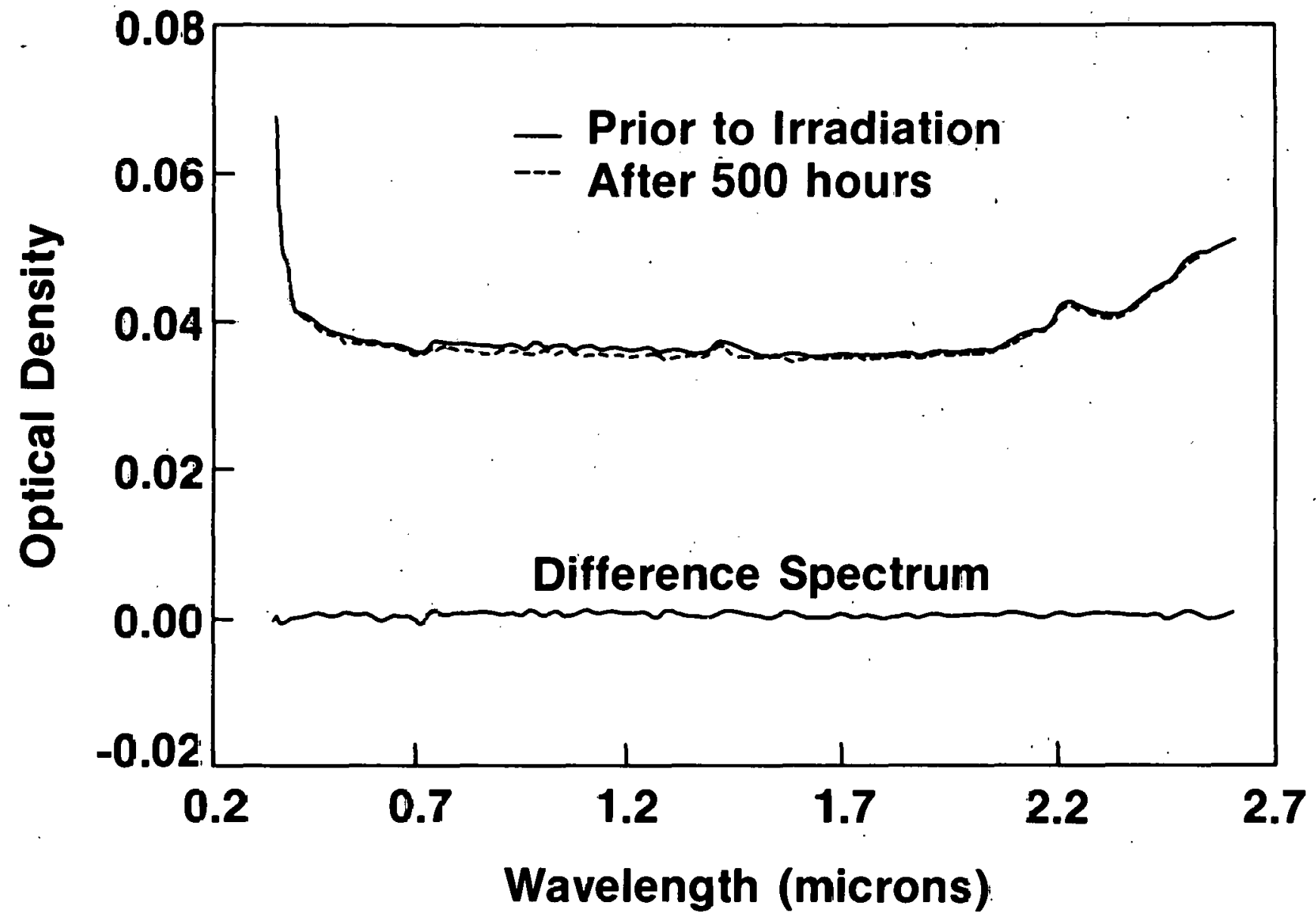

Figure 6. The Wavelength Dependence of the Optical Density for CGW-7809 Glass after Exposure to a 10-Sun Solar Simulator 


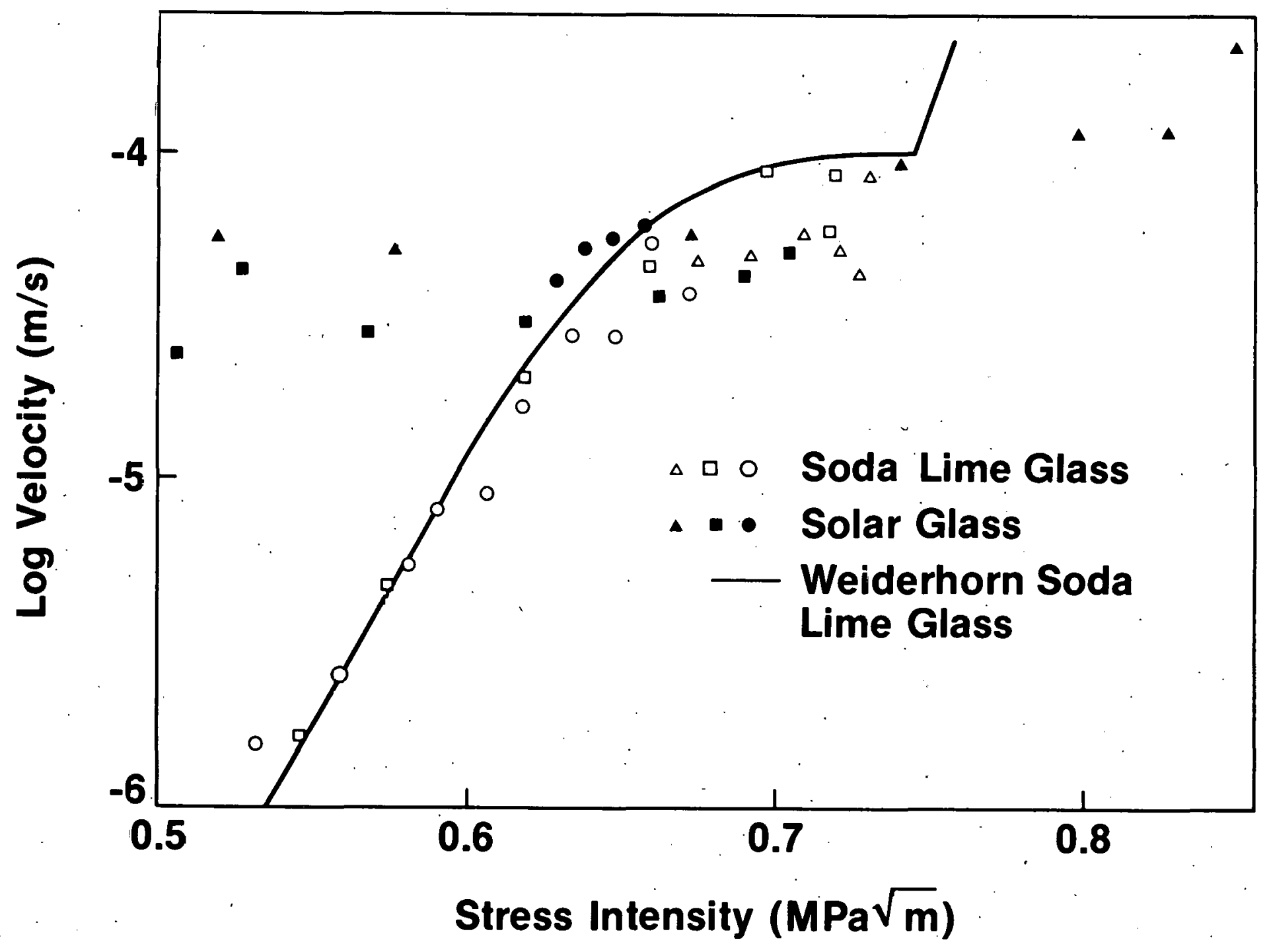

Figure 7. Stress Corrosion of CGW-7809 Solar Glass and Soda-Lime Glass at $35 \%$ R.H. and $22{ }^{\circ} \mathrm{C}$ 
that of float glass, while the solar absorption of the glass is much lower than for float glass. Changes in solar optical absorption due to weathering and solarization were found to be negligible. The fracture toughness of the glass was found to be greater than for float glass.

\section{REFERENCES}

1. Brandhourst, H. W., Jr., Terrestrial Photovoltaics Measurement Procedures, NASA TM 73702, ERDA/NASA/1022-77/16 (1975).

2. Vitko, J., Jr. and Shelby, J. E., to be published.

3. White, J. F. and Silverman, W. B.; J. Am. Cer. Soc. 33 (1950) 252.

4. Wnng, J. und Angell, C. A., Glasss Structure by Spectroscupy, (Marcel Dekker Inc., N.Y., Basel, 1976) 250 .

5. Barker, L. M., Short Rod $\mathrm{K}_{\mathrm{JC}}$ Measurments of $\mathrm{Al}_{2} \mathrm{O}_{3}$, in: Bradt, R. C., Hasselman, D. P. H., and Lange, F.F. (eds.) Fracture Mechanics of Ceramics, Vol. 3 (Plenum Publishing Corp., 1978).

6. Barker, L. M., Method of Analyzing Slow Crack Growth Data from the TerraTek Firaclumeter, private communication.

7. Weiderhorn, S. M., Subcritical Crack Growth in Ceramics, in: Bradt, R. C., Hasselman, D. P. H., and Lange, F. F. (eds.) Fracture Mechanics of Ceramics, Vol. 2 (Plenum Publishing Corp., 1978). 